\title{
A cross-sectional study of HIV and syphilis infections among male students who have sex with men (MSM) in northeast China: implications for implementing HIV screening and intervention programs
}

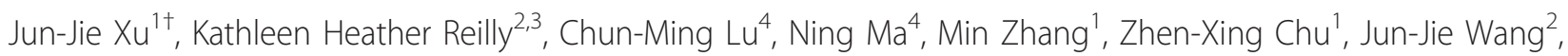
Ke Yun ${ }^{1}$ and Hong Shang ${ }^{1 * \dagger}$

\begin{abstract}
Background: China has 76.2 million high school and college students, in which the number of reported HIV/AIDS cases is increasing rapidly. Most of these cases are attributed to male-to-male sexual contact. Few studies have explored HIV prevalence and behavioural characteristics of Chinese male students who have sex with men (MSM).

Methods: A cross-sectional study of MSM high school and college students in Liaoning Province was conducted. Data were collected through face-to-face interviews and blood specimens were obtained and tested for HIV and syphilis.

Results: There were 436 eligible participants. HIV and syphilis prevalence was 3.0\% and 5.0\%, respectively. In multivariate analysis, sexual orientation known by family members (OR: 7.3; 95\% Cl: 1.5-34.6), HIV/AIDS information obtained from clinical doctors (OR: 6.7; 95\% Cl: 1.7-25.9), HIV/AIDS information obtained through free educational services and materials such as voluntary counseling and testing (VCT) and condom distribution services (OR: 0.2; 95\% Cl: 0.4-1.0), inconsistent condom use (OR: 5.7; 95\%: 1.3-25.3), sexual partner experienced anal bleeding after insertive anal intercourse (OR: 6.8; 95\% Cl: 1.6-28.4), and history of illegal drug use (OR: 18.9; 95\% Cl: 2.2-165.3) were found to be significantly associated with HIV infection.

Conclusions: Greater effort should be made towards stemming the HIV and syphilis epidemics among Chinese student MSM. Immediate screening and comprehensive interventions towards student MSM should be implemented in order to curb the spread of HIV. Family and school-based interventions should be considered to target this educated, yet vulnerable, population.
\end{abstract}

Keywords: HIV syphilis, China, men who have sex with men (MSM), high school students, college students

\footnotetext{
* Correspondence: hongshang100@hotmail.com

† Contributed equally

${ }^{1}$ From Key Laboratory of AIDS Immunology of Ministry of Health, Department of Laboratory Medicine, No.1 Hospital of China Medical University, Shenyang 110001, China

Full list of author information is available at the end of the article
}

(c) 2011 Xu et al; licensee BioMed Central Ltd. This is an Open Access article distributed under the terms of the Creative Commons 


\section{Background}

Acquired Immune Deficiency Syndrome (AIDS) is currently one of the leading causes of death among 15 to 24-year adolescent and young adults [1]. Reducing adolescent sexual risk behaviour has become an international public health priority [1]. In China, MSM accounted for $12.2 \%$ of new HIV cases in 2007 [2], while in 2009 the proportion increased to $32.5 \%$ of all new HIV cases [3]. Several large cities in China have found a steady increase in HIV prevalence among MSM [4-7]. It is important for China to curb the spread of the HIV epidemic among this vulnerable population. Several recent studies of Chinese MSM found that between $27.9 \%-72.3 \%$ of MSM study participants were college educated $[8,9]$, which is significantly higher than the percentage of higher education among other high-risk groups in China including female sex workers (6.4-7.1\%) $[10,11]$ and injection drug users $(0.0-8.1 \%)[12,13]$. While Chinese students are generally not considered to be at high risk for HIV [2], only a few studies with small samples sizes have been conducted to analyze the risk behaviours for HIV infection among Chinese student MSM [14-16].

China has the largest number of college students in the world. By the end of 2009, there were an estimated 46.4 million high school students and 29.8 million college students in China, approximately half of whom are male [17]. Chinese studies have found that 3.7\%-10.3\% $[16,18]$ of male college students reported ever having at least one episode of sexual intercourse with another male. Those students who reported homosexual behaviours had more sexual partners and higher proportions of unprotected sex behaviour compared with non-MSM male students [16].

Liaoning Province is the economic and commercial hub of northeast China with one of the largest numbers of college and high school students. Recent surveys of Liaoning MSM found a significantly higher prevalence of syphilis compared with Beijing MSM (25.4\% vs.11.2\%, respectively) $[8,19]$ and syphilis infection was independent risk factor for both HIV infection and incidence $[7,8,19]$. Syphilis prevalence appears to be rapidly increasing among Chinese MSM [6,7]. Syphilis infection is a biomarker for unprotected sex, and may facilitate the acquisition of HIV [20].

Recently Beijing, Hefei, Chongqing, Hangzhou Cities have detected HIV infections among college and high school students [15,21-23]. In Hangzhou city, students accounted for $3.7 \%$ of newly reported HIV cases between January 1, 2009 to May 31, 2010, and the prevalence of HIV among college students reached $0.4 \%$ (8/ 2000), most these cases were MSM [24]. The rapidly increasing trend of HIV infections among Hangzhou college students is alarming, as the number of reported HIV cases has increased from one in 2005, three in 2007, six in 2008, and to nineteen in 2009 [25]. According to a 2010 report from Chinese Ministry of Health, among nationally reported HIV/AIDS cases, the proportion of HIV among students increased from $0.96 \%$ to $1.04 \%$ to $1.37 \%$ in the years 2007, 2008 and 2009. During this time period (2007-2009), the proportion of HIV cases among 20-24 year old students increased from $20.3 \%$ to $39.8 \%$ and the proportion of homosexually transmitted cases increased from $8 \%$ to $36.9 \%$ [26].

Understanding the prevalence of HIV and high risk behaviour among Chinese student MSM is important in order to determine how to design interventions among this population to curb the HIV epidemic. The current study was conducted in order to determine HIV and syphilis prevalences, high risk sexual behaviours, drug use, and other factors related to HIV infection among Liaoning MSM students.

\section{Methods}

\section{Participant enrolment}

From April 2008 to January 2009, MSM students were approached and invited to participate in this study by outreach staff from non-governmental organizations that specifically serve the MSM community. Participants were eligible to participate in this study if they were male, at least 18 years of age, currently a high school or college student, reported at least one episode of receptive or insertive anal sex with a male sexual partner in the past 12 months, and were able and willing to provide written informed consent. Study participants were asked to refer their eligible sexual partners to participate in this study.

Data were collected on demographics, sexual behaviour, history of drug use (self-report of ever using opium, heroin, methamphetamine, morphine, cannabis, cocaine, dolantin, ketamine, triazolam, or amphetamine), and medical history through standardized questionnaires that were administrated though face-to-face interviews by trained local physicians. Blood specimens were obtained and tested for HIV and syphilis. Those who tested positive for HIV or syphilis were referred to treatment at a local hospital. All participants were given general information about HIV and syphilis and were informed how to practice safe sex through pre- and post-test counseling provided by this study. Each participant was compensated 50 RMB cash (\$7 USD) or equivalent gifts as compensation for the cost of their time and transportation.

\section{Ethics}

The study protocol and informed consent forms were approved by the Institutional Review Boards of the 
China Medical University and Liaoning Provincial Center for Disease Control and Prevention (CDC). Written informed consent was collected for each participant at enrolment. Participation in this study was completely voluntary and those who decided to participate could refuse to answer any questions they did not feel comfortable answering.

\section{Laboratory testing}

Blood samples were tested for HIV and syphilis antibodies. The presence of HIV-1 antibody was tested for through enzyme-linked immunosorbent assay (ELISA) (Vironostika HIV-1 Microelisa System; BioMe'rieux, Durham, NC). Positive tests were confirmed by HIV-1/2 Western blot assay (HIV Blot 2.2 WB; Genelabs Diagnostics, Singapore). Syphilis serology was determined through rapid plasma reagin (RPR, Diagnosis t; Shanghai Kehua, China). Serum specimens that were positive for TPPA (TPPA, Serodia, Japan) were retested for rapid plasma reagin (RPR, Diagnosis t; Shanghai Kehua, China) assay, Subjects with serum positive for both TPPA and RPR were determined to be currently infected with syphilis. Syphilis tests and HIV antibody screening were conducted at local CDCs (Shenyang, Anshan, Fushun, Dalian and Benxi CDCs) and HIV WB confirmation was conducted at the Liaoning provincial CDC.

\section{Data analysis}

Questionnaires were double entered and then checked for accuracy using Epi Data software (Epi Data Association, Odense, Denmark, version 3.02). Data were analyzed using SPSS version 16.0 (Chicago, IL, USA). Normally distributed continuous variables were described with means and non-normally distributed continuous variables were described with medians. Odds ratios (OR) and 95\% confidence intervals $(\mathrm{CI})$ were calculated. Categorical data were described and analyzed by frequency and Chisquared tests. Univariate logistic regression and forward stepwise multivariate logistic regression were used to determine adjusted odds ratios (aOR) for HIV infection related risk-factors. Marginally significant variables with $\mathrm{p}$ $<0.20$ in univariate analysis were included in multivariate analysis. Variables with $\mathrm{p}<0.1$ were retained in the final multivariate logistic model in a forward stepwise manner.

\section{Results}

\section{Demographic characteristics of MSM students}

A total of 436 eligible student MSM completed the survey. Demographic characteristics of study participants are shown in Table 1 . The majority of study participants were $\leq 20$ years of age $(54.4 \%)$, single $(98.2 \%)$, permanent residents of Liaoning Province (90.6\%), Han ethnicity $(88.5 \%)$, high school students (62.4\%), identified as
Table 1 Demographic characteristics of Liaoning MSM students

\begin{tabular}{|c|c|c|}
\hline Characteristics & Number & Proportion (\%) \\
\hline \multicolumn{3}{|l|}{ Age (yrs.) } \\
\hline$\leq 20$ & 237 & 54.4 \\
\hline$>20$ & 199 & 45.6 \\
\hline \multicolumn{3}{|l|}{ Marriage status } \\
\hline Single & 428 & 98.2 \\
\hline Cohabitating & 1 & 0.2 \\
\hline Married & 7 & 1.6 \\
\hline \multicolumn{3}{|l|}{ Permanent residence } \\
\hline Liaoning Province & 395 & 90.6 \\
\hline Other province & 41 & 9.4 \\
\hline \multicolumn{3}{|l|}{ Nationality } \\
\hline Han & 386 & 88.5 \\
\hline Non-Han & 50 & 11.5 \\
\hline \multicolumn{3}{|l|}{ Currently level of education } \\
\hline College or above & 164 & 37.6 \\
\hline High school and below & 272 & 62.4 \\
\hline \multicolumn{3}{|l|}{ Sexual orientation } \\
\hline Homosexual orientation & 252 & 57.8 \\
\hline Bisexual orientation & 155 & 35.6 \\
\hline Heterosexual orientation & 4 & 0.9 \\
\hline Sexual orientation undetermined & 25 & 5.7 \\
\hline \multicolumn{3}{|l|}{ Main location to seek homosexual partners } \\
\hline Internet & 322 & 73.9 \\
\hline Park/public bathroom & 35 & 8.0 \\
\hline Bathing room/sauna/massage room & 27 & 6.2 \\
\hline Bar/night club/tearoom & 26 & 6.0 \\
\hline Other places & 26 & 6.0 \\
\hline
\end{tabular}

homosexual (57.8\%), and met their sex partners on the internet (73.9\%).

\section{HIV-related knowledge}

Table 2 illustrates the relatively high HIV-related knowledge exhibited by study participants. Approximately $90 \%$ knew the correct answers to HIV prevention questions, with the exception of the question about acquiring HIV through mosquito bites, which only $67.4 \%$ answered correctly.

\section{Drug use and high risk sexual behaviour}

Only 13.5\% (59/436) of MSM students' sexual orientation were known by their family, of which $10.8 \%$ (47/ $436)$ and $6.7 \%$ (29/436) were known by their mothers and fathers, respectively. The average age of first sexual intercourse was $18.5 \pm 5.9$ years, in which 428 (98.2\%) had insertive anal intercourse with male sexual partners and $8(1.8 \%)$ had vaginal intercourse with female partners. Approximately one-third $(\mathrm{n}=146,33.5 \%)$ had ever had an HIV test. In the most recent 6 months, 371 (85.1\%) had anal intercourse with male sexual partners. 


\begin{tabular}{|c|c|}
\hline $\begin{array}{l}\text { HIV/AIDS knowledge and prevention related } \\
\text { questions }\end{array}$ & $\begin{array}{l}\text { Correctly } \\
\text { answered(\%) }\end{array}$ \\
\hline Whether PLWH can be detected from appearance & 399(91.5\%) \\
\hline \multicolumn{2}{|l|}{ Whether behaviors can result in HIV infection } \\
\hline Blood transfusion from PLWH & $426(97.7 \%)$ \\
\hline Sharing syringe with PLWH & $414(95.0 \%)$ \\
\hline Having dinner with PLWH & $391(89.7 \%)$ \\
\hline $\begin{array}{l}\text { Birth and breast-feeding from HIV infected } \\
\text { mothers }\end{array}$ & $424(97.2 \%)$ \\
\hline Mosquito bites & $294(67.4 \%)$ \\
\hline $\begin{array}{l}\text { Limiting sexual partners to one single HIV- } \\
\text { negative partner }\end{array}$ & $399(91.5 \%)$ \\
\hline $\begin{array}{l}\text { Correctly using condom during each act of } \\
\text { sexual intercourse }\end{array}$ & $418(95.9 \%)$ \\
\hline
\end{tabular}

*, PLWH, people living with HIV;

In the most recent 6 months, $57.1 \%(249 / 436)$ of participants had one male sexual partner, 28.7\% (125/436) had 2-3 male sexual partners, $7.6 \%(33 / 436)$ had 4-5 male sexual partners, and 6.7\% (29/436) had > 5 male sexual partners. Slightly more than half $(n=259,59.4 \%)$ never used or seldom used condoms with male sexual partners in the most recent six months. When having anal sex with regular (non-casual) male sexual partners, only 180 (48.5\%) always used a condom. Slightly more ( $\mathrm{n}=254$, $58.3 \%$ ) always used a condom when they had anal sex with occasional sexual partners. Most study participants did not use a condom during insertive oral sex (65.5\%) or receptive oral sex $(65.0 \%)$. One quarter $(n=104$, $23.9 \%)$ experienced anal bleeding after receptive intercourse.

In the most recent six months, 7 (1.6\%) purchased sex from male partners and $25(5.7 \%)$ once sold sex to male partners. A small proportion of the study population $(\mathrm{n}=$ $43,9.9 \%$ ) had engaged in heterosexual behaviour, in which $21(48.8 \%)$ failed to use condoms with female sexual partners. In the past 12 months, 55 (12.6\%) study participants had sexually transmitted disease (STD) symptoms (pain during urination, genital burning sensation, or abnormal urethral discharge) in the past year, in which $98.2 \%$ $(54 / 55)$ went to see a private doctor or self-treated.

Several study participants $(\mathrm{n}=25,5.7 \%)$ knew that their male sexual partners were infected with HIV, while 138 (31.7\%) declined to used condoms with their regular male sexual partners even if they knew their regular male sexual partner was infected with HIV. Very few ( $\mathrm{n}=8,1.8 \%$ ) self-reported to have ever used any of the listed illegal drugs and none had ever injected drugs.

\section{HIV/syphilis prevalence and HIV infection correlates}

The prevalence of HIV among Liaoning student MSM was $3.0 \%$ (13/436) (95\% confidence interval (CI) 1.6\%-
$5.0 \%)$. The prevalence of syphilis was 5.0\% (22/436) (95\% CI $3.2 \%-7.5 \%)$. Table 3 presents the univariate and multivariate logistic analyses of variables associated with HIV among Liaoning MSM students. In multivariate analysis, sexual orientation known by family members (OR: 7.3; 95\% CI: 1.5-34.6), HIV/AIDS information obtained from clinical doctors (OR: 6.7; 95\% CI: 1.7-25.9), HIV/AIDS information obtained through free educational services and materials such as voluntary counselling and testing (VCT) and condom distribution programs (OR: 0.2; 95\% CI: 0.4-1.0), inconsistent condom use (OR: 5.7; 95\%: 1.325.3), sexual partner experienced anal bleeding after insertive anal intercourse (OR: 6.8; 95\% CI: 1.6-28.4), and history of illegal drug use (OR: 18.9; 95\% CI: 2.2-165.3) were found to be significant associated for HIV infection.

\section{Discussion}

To our knowledge, this is the largest epidemiological study to estimate HIV and STD prevalence and describe the related risk behaviours among Chinese male high school and university student MSM. Understanding this population is important in order to design interventions to curb China's HIV epidemic.

The HIV prevalence among this group of Liaoning student MSM was $3.0 \%$, which is over fifty times higher than the Chinese general population $(0.057 \%)$ [3]. This prevalence is also higher than that reported among MSM students in Beijing (2.3\%) [14] and Hefei(1.7\%) [15]. The prevalence of syphilis in this survey (5.0\%), however, is lower than that reported among MSM students in Beijing (7.43\%) [14] and Hefei(7.4\%) [15]. The prevalences of HIV and syphilis were markedly lower than that reported among MSM of all ages in Shenyang City, Liaoning Province (HIV 5.7\% and syphilis 25.4\%) [8].

Although the number of high school and college students is the largest in the world and $3.7 \%-10.3 \%$ of Chinese male college students report engaging in sexual activity with men $[16,18]$, as yet, there have been few HIV/STD prevention programs that have targeted this vulnerable population. The relatively high prevalence of HIV and syphilis found in this survey demonstrates that it is urgent for the Chinese government to take action and target prevention interventions aimed at this group.

The current study also found a seemingly contradictory phenomenon, those MSM whose sexual orientation was known by family members were more likely to be infected with HIV, while a previous study of Chinese MSM in Hong Kong found that those who were open about their MSM status were more likely to use condoms [27]. It is possible that participants who were HIV positive were already aware of their status and had disclosed their status to their parents. Sexual orientation known by family could also be considered a proxy for openness of sexuality. Future studies should investigate 
Table 3 Prevalence, univariate, and multivariate logistic analyses of HIV infection associated factors among Liaoning MSM students

\begin{tabular}{|c|c|c|c|c|c|c|}
\hline \multirow[t]{2}{*}{ Factors } & & \multirow[t]{2}{*}{$\mathrm{N}$} & \multirow[t]{2}{*}{$\begin{array}{l}\text { Prevalence } \\
\quad(\%)\end{array}$} & \multirow{2}{*}{$\begin{array}{c}\begin{array}{c}\text { Univariate } \\
\text { Analysis }\end{array} \\
\text { OR } \\
(95 \% \mathrm{Cl})\end{array}$} & \multicolumn{2}{|c|}{$\begin{array}{l}\text { Multivariate } \\
\text { Analysis }\end{array}$} \\
\hline & & & & & $\begin{array}{c}\text { AOR } \\
(95 \% \mathrm{Cl})\end{array}$ & $\mathbf{P}$ \\
\hline \multirow[t]{2}{*}{ Permanent residence } & Liaoning Province & 395 & 13(3.3) & & & \\
\hline & $\begin{array}{l}\text { None-Liaoning } \\
\text { Province }\end{array}$ & 41 & $0(0.0)$ & $\begin{array}{c}0.3 \\
(0.0-5.8)\end{array}$ & & \\
\hline \multirow[t]{2}{*}{ Age (yrs.) } & $\leq 20$ & 237 & $6(2.5)$ & & & \\
\hline & $>20$ & 199 & $7(3.5)$ & $\begin{array}{c}1.4 \\
(0.5-4.2)\end{array}$ & & \\
\hline \multirow[t]{2}{*}{ Nationality } & Han & 386 & $12(3.1)$ & & & \\
\hline & Non-Han & 50 & $1(2.0)$ & $\begin{array}{c}1.6 \\
(0.2-12.3)\end{array}$ & & \\
\hline \multirow[t]{2}{*}{ Currently level of education } & College or above & 272 & $7(2.6)$ & & & \\
\hline & $\begin{array}{l}\text { High school and } \\
\text { below }\end{array}$ & 164 & $6(3.7)$ & $\begin{array}{c}1.4 \\
(0.5-4.3)\end{array}$ & & \\
\hline \multirow[t]{2}{*}{ Sexual orientation known by family members } & No & 377 & $9(2.4)$ & & & \\
\hline & Yes & 59 & $4(6.8)$ & $\begin{array}{c}3.0 \\
(0.9-10.0)\end{array}$ & $\begin{array}{c}7.3 \\
(1.5-34.6)\end{array}$ & 0.013 \\
\hline \multirow[t]{2}{*}{ Knowledge of whether PLWH can be detected from appearance } & No & 399 & $9(2.3)$ & & & \\
\hline & Yes & 26 & $4(15.4)$ & $\begin{array}{c}5.3 \\
(1.5-18.0)\end{array}$ & & \\
\hline \multirow[t]{2}{*}{ Knowledge of whether input blood from PLWH can infect HIV } & Yes & 426 & $11(2.6)$ & & & \\
\hline & No & 10 & $2(20.0)$ & $\begin{array}{c}9.4 \\
(1.8-50.0)\end{array}$ & & \\
\hline \multirow[t]{2}{*}{ Knowledge of whether sharing syringe with PLWH can infect HIV } & Yes & 414 & $11(2.7)$ & & & \\
\hline & No & 22 & $2(9.5)$ & $\begin{array}{c}3.7 \\
(0.8-17.6)\end{array}$ & & \\
\hline \multirow[t]{2}{*}{ HIV/AIDS knowledge scores } & $\geq 8$ & 244 & $7(2.9)$ & & & \\
\hline & $<8$ & 192 & $6(3.1)$ & $\begin{array}{c}1.1 \\
(0.4-3.3)\end{array}$ & & \\
\hline Source of HIV/AIDS knowledge & Yes & 229 & $4(1.7)$ & & & \\
\hline Television & No & 207 & $9(4.3)$ & $\begin{array}{c}2.6 \\
(0.8-8.4)\end{array}$ & & \\
\hline \multirow[t]{2}{*}{ Clinical doctors } & No & 358 & $7(2.0)$ & & & \\
\hline & Yes & 78 & $6(7.7)$ & $\begin{array}{c}4.2 \\
(1.4-12.8)\end{array}$ & $\begin{array}{c}6.7 \\
(1.7-25.9)\end{array}$ & 0.006 \\
\hline \multirow{2}{*}{$\begin{array}{l}\text { Free education services and materials, such as VCT and provision } \\
\text { of condoms }\end{array}$} & No & 230 & $10(4.3)$ & & & \\
\hline & Yes & 206 & $3(1.5)$ & $\begin{array}{c}0.3 \\
(0.1-1.2)\end{array}$ & $\begin{array}{c}0.2 \\
(0.4-1.0)\end{array}$ & 0.060 \\
\hline \multirow[t]{2}{*}{ Condom use with casual male sexual partners } & Always use & 254 & $3(1.2)$ & & & \\
\hline & $\begin{array}{l}\text { Occasionally/never } \\
\text { use }\end{array}$ & 182 & $10(5.5)$ & $\begin{array}{ll} & 4.9 \\
(1.3-17.9) & -1\end{array}$ & $\begin{array}{c}5.7 \\
(1.3-25.3)\end{array}$ & 0.023 \\
\hline \multirow[t]{2}{*}{ Unprotected receptive anal sex in past 6 months } & No & 203 & $4(2.0)$ & $\begin{array}{c}2.0 \\
(0.6-6.7)\end{array}$ & & \\
\hline & Yes & 231 & $9(3.9)$ & & & \\
\hline \multirow[t]{2}{*}{ Anal bleeding after receptive anal intercourse } & No & 330 & $8(2.4)$ & & & \\
\hline & Yes & 104 & $5(4.8)$ & $\begin{array}{c}2.0 \\
(0.7-6.4)\end{array}$ & & \\
\hline \multirow{2}{*}{$\begin{array}{l}\text { Sexual partner experienced anal bleeding after insertive anal } \\
\text { intercourse }\end{array}$} & No & 360 & $7(1.9)$ & & & \\
\hline & Yes & 76 & $6(7.9)$ & $\begin{array}{c}4.3 \\
(1.4-13.3)\end{array}$ & $\begin{array}{c}6.8 \\
(1.6-28.4)\end{array}$ & 0.009 \\
\hline \multirow[t]{2}{*}{ Has ever purchased or sold sex with male partners } & No & 409 & $12(2.9)$ & & & \\
\hline & Yes & 27 & $1(3.7)$ & $\begin{array}{c}1.3 \\
(0.2-10.2)\end{array}$ & & \\
\hline
\end{tabular}




\begin{tabular}{|c|c|c|c|c|c|c|}
\hline \multirow[t]{2}{*}{ History of illegal drug use } & No & 429 & 11(2.6) & & & \\
\hline & Yes & 8 & $2(25.0)$ & $\begin{array}{c}12.6 \\
(3.3-69.8)\end{array}$ & $\begin{array}{c}18.9 \\
(2.2-165.3)\end{array}$ & 0.008 \\
\hline \multirow[t]{2}{*}{ STD symptoms* in the past year } & No & 381 & $9(2.4)$ & & & \\
\hline & Yes & 55 & $4(7.3)$ & $\begin{array}{c}3.2 \\
(1.0-10.9)\end{array}$ & & \\
\hline \multirow[t]{2}{*}{ Saw a private doctor in the past year } & No & 410 & $11(2.7)$ & & & \\
\hline & Yes & 26 & $2(7.7)$ & $\begin{array}{c}3.0 \\
(0.6-14.4)\end{array}$ & & \\
\hline \multirow[t]{2}{*}{ Self-treated STD in the past year } & No & 397 & $10(2.5)$ & & & \\
\hline & Yes & 39 & $3(7.7)$ & $\begin{array}{c}3.2 \\
(0.8-12.3)\end{array}$ & & \\
\hline \multirow[t]{2}{*}{ Had male sexual partners who are infected with HIV } & No & 411 & $11(2.7)$ & & & \\
\hline & Yes & 25 & $2(8.0)$ & $\begin{array}{c}3.2 \\
(0.7-15.1)\end{array}$ & & \\
\hline \multirow[t]{2}{*}{ Syphilis } & Negative & 401 & $11(2.7)$ & & & \\
\hline & Positive & 22 & $2(9.1)$ & & & \\
\hline
\end{tabular}

*STD symptoms: urination pain, penis burning, or abnormal urethral discharge. OR, odds ratio; AOR, adjusted odds ratio; VCT, voluntary counseling and testing.

the effects of social support and openness of sexuality on high risk behaviour among Chinese MSM.

Somewhat paradoxically, those who received HIV/ AIDS education from a clinician were more likely to be infected with HIV than those who did not receive HIV education from a clinician. Due to the cross-sectional nature of this study, it is difficult to discern if HIVrelated knowledge was gained prior to engaging in high risk behaviour. Those who had an STI and were more susceptible to HIV infection may be more likely to see a clinician and obtain HIV/STI prevention information. Overall, HIV/AIDS knowledge was not statistically correlated with HIV infection, which may indicate a low perception of risk. The utilization of free HIV education services and materials such as VCT and condoms distribution services, however, were negatively associated with HIV infection. Comprehensive interventions, which incorporate VCT and the provision of free condoms, should be considered since it appears as though HIV knowledge is not enough to prevent HIV among Chinese student MSM.

Inconsistent condom use with casual male sex partners was found to be independently associated for HIV infection. Low condom usage is of particular concern in this study population since several reported low condom use with female partners and with HIV positive partners. A study in Beijing also reported low condom use among college student MSM [14]. Peer education has been demonstrated to be an effective means of reaching both MSM and student populations to promote healthy behaviours, which may be used to reduce their risk of HIV infection [28-31].

This study also found that bleeding after insertive anal intercourse was associated with HIV infection. A study in Mexico City determined that MSM who bled after anal sex were more likely to be HIV positive compared with those that did not experience bleeding [32]. Ruptured mucous membranes that result from anal sex may facilitate the entry of the virus. MSM should be encouraged to use condoms with water-based lubricants during anal sex in order to minimize the risk of anal and rectal bleeding and general HIV/STD transmission.

The current study found that illegal drug use, but not injection drug use, was independently associated with HIV infection among MSM students. Injection drug use has historically been found to be a primary risk factor for HIV in China [33], but studies of MSM have also found use of non-injection drugs to be associated with HIV infection. These studies found that methamphetamine, amyl nitrate, and Viagra were the most common drugs associated with HIV infection [34,35]. The current study did not gather detailed information on types of drugs used, but future interventions should discourage illegal drug use, in general, in order to prevent high risk behaviour resulting from a loss of inhibition.

This study is subject to several limitations. This was a cross-sectional study and therefore temporal associations cannot be inferred. The survey asked questions about sensitive topics and participants may not have felt comfortable answering accurately. In order to minimize recall bias, questions were framed in terms of behaviour in the last 6 months; however, this may not be indicative of usual behaviour. Selection bias may have influenced the results of this study and since the survey subjects were a convenience sample of student MSM who live in Liaoning Province, the results of this study may not be generalizeable to the greater student MSM population. Since participants were asked to recruit their sexual 
partners there may have been some bias in the HIV and STI estimates. Although multivariate analysis was used to address possible confounding by study variables, it is possible that other confounding occurred by variables not measured in this study.

\section{Conclusions}

The prevalence of HIV among MSM students has reached $3.0 \%$, which is over fifty times higher than the Chinese general population. History of illegal drug use, but not injection drug use, was found independently associated with HIV infection. Approximately one-third (33.5\%) had ever had an HIV test. Most MSM students have a good understanding of the means of HIV/AIDS transmission and prevention. However, high proportions of participants failed to use condoms with steady and casual male partners, putting them at high risk for HIV infection and transmission. Only about five percent of MSM students' sexual orientations were known by their parents. The findings indicate that MSM students are a vulnerable population for HIV infection in China. HIV screening should be prioritized for this group. Future interventions should discourage illegal drug use in order to prevent high risk behaviour resulting from a loss of inhibition. The sole strategy of HIV/AIDS knowledge promotion is not enough to prevent HIV epidemic among this population. Widespread family and schoolbased based HIV prevention strategies should be encouraged by utilizing China's mainstream media. This study's results have important significance for designing immediate and targeted interventions to curb HIV epidemic among this population.

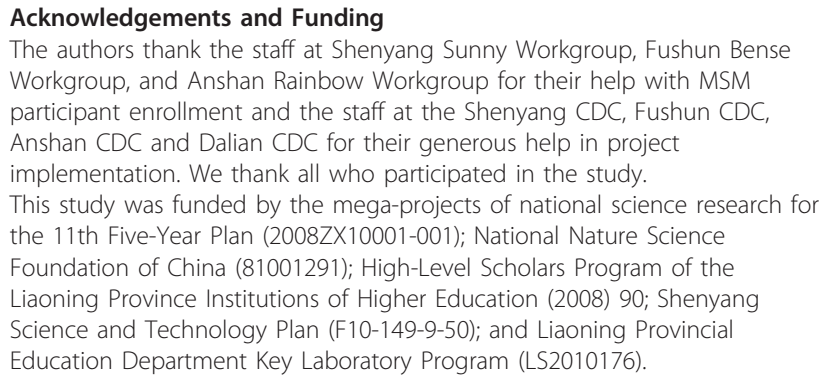

\begin{abstract}
Author details
${ }^{1}$ From Key Laboratory of AIDS Immunology of Ministry of Health, Department of Laboratory Medicine, No.1 Hospital of China Medical University, Shenyang 110001, China. ${ }^{2}$ National Center for AIDS/STD Control and Prevention, Chinese Center for Disease Control and Prevention(CDC), Beijing, China. ${ }^{3}$ Tulane University Health Sciences Center, School of Public Health and Tropical Medicine, New Orleans, LA, USA. ${ }^{4}$ Liaoning Provincial CDC, Shenyang, China.
\end{abstract}

\section{Authors' contributions}

HS and CML participated in the design of the study protocol, JJX and KHR wrote the manuscript. MN and ZM supervised the implementation of the study. JJW, ZXC and KY performed the analysis of the data. All authors read and approved the final manuscript.

\section{Competing interests}

The authors declare that they have no competing interests.

Received: 27 December 2010 Accepted: 10 May 2011

Published: 10 May 2011

\section{References}

1. Donenberg GR, Paikoff R, Pequegnat W: Introduction to the special section on families, youth, and HIV: Family-based intervention studies. J Pediatr Psychol 2006, 31(9):869-873.

2. State Council AIDS Working Committee Office, China Ministry of Health, UN Theme Group on HIV/AIDS in China: A Joint Assessment of HIV/AIDS Prevention, Treatment and Care in China. Beijing, China: State Council AIDS Working Committee Office; 2007 [http://www.chinaids.org.cn], 2010.

3. Ministry of Health, People's Republic of China: 2009 estimates for the HIV/ AIDS epidemic in China: Ministry of Health, People's Republic of China, Joint United Nations Programme on HIV/AIDS. World Health Organization; 2010 [http://www.chinaids.org.cn].

4. Zhang D, Bi P: Changes in HIV prevalence and sexual behavior among men who have sex with men in a northern Chinese city: 2002-2006. J Infect 2007, 55(5):456-463.

5. Jia M, Luo H, Ma Y, Wang N, Smith K, Mei J, Lu R, Lu J, Fu L, Zhang Q: The HIV epidemic in Yunnan Province, China, 1989-2007. JAIDS 2010, 53(Suppl):S34-S40.

6. Ma X, Zhang Q, He X, Sun W, Yue H, Chen S, Raymond HF, Li Y, Xu M, Du H: Trends in prevalence of HIV, syphilis, hepatitis C, hepatitis B, and sexual risk behavior among men who have sex with men: results of 3 consecutive respondent-driven sampling surveys in Beijing, 2004 through 2006. JAIDS 2007, 45(5):581-587.

7. Feng TJ, Liu XL, Cai YM, Pan P, Hong FC, Jiang WN, Zhou H, Chen XS: Prevalence of syphilis and human immunodeficiency virus infections among men who have sex with men in Shenzhen, China: 2005 to 2007. Sex Transm Dis 2008, 35(12):1022-1024.

8. Xu JJ, Zhang M, Brown K, Reilly K, Wang H, Hu Q, Ding H, Chu Z, Bice T, Shang H: Syphilis and HIV Seroconversion Among a 12-Month Prospective Cohort of Men Who Have Sex With Men in Shenyang, China. Sex Transm Dis 2010, 37(7):432-439.

9. Ruan Y, Jia Y, Zhang X, Liang H, Li Q, Yang Y, Li D, Zhou Z, Luo F, Shi W: Incidence of HIV-1, Syphilis, Hepatitis B, and Hepatitis C Virus Infections and Predictors Associated With Retention in a 12-Month Follow-Up Study Among Men Who Have Sex With Men in Beijing, China. JAIDS 2009, 52(5):604-610.

10. Ding Y, Detels R, Zhao Z, Zhu Y, Zhu G, Zhang B, Shen T, Xue X: HIV infection and sexually transmitted diseases in female commercial sex workers in China. JAIDS 2005, 38(3):314-319.

11. Tian LG, Ma ZE, Ruan YH, Cao XY, Huang JP, Wang DR, Zhu GP, Yao HM, Han L, Hao C: Incidence rates of human immunodeficiency virus and syphilis as well as the rate of retention in a 6-month follow-up study of female sex workers in areas with heavy drug use in Xichang of Sichuan province, China. Zhonghua Liu Xing Bing Xue Za Zhi 2006, 27(11):939-942.

12. Ruan Y, Chen K, Hong K, He Y, Liu S, Zhou F, Qin G, Chen J, Xing H, Shao Y: Community-based survey of HIV transmission modes among intravenous drug users in Sichuan, China. Sex Transm Dis 2004, 31(10):623-627.

13. Zhang Y, Shan H, Trizzino J, Ruan Y, Beauchamp G, Māsse B, Ma J, Rui B, Wang J, Liu M: HIV incidence, retention rate, and baseline predictors of HIV incidence and retention in a prospective cohort study of injection drug users in Xinjiang, China. Int J Infect Dis 2007, 11(4):318-323.

14. Zheng JD: Study on HIV high risk behaviors and their correlates among men who have sex with men in college students of Beijing. Chi CDC; 2008.

15. Zhu J, Zhang H, Wu H: High risk sexual behavior and HIV/STD infection rate among 122 MSM from students. Chin J AIDS STD 2007, 13(4):350-352.

16. Cong L, Ono-Kihara M, Xu G, Ma Q, Pan X, Zhang D, Homma T, Kihara M: The characterisation of sexual behaviour in Chinese male university students who have sex with other men: A cross-sectional study. BMC Public Health 2008, 8(1):250.

17. The central government website: Ministry of Education released the 2009 National Education Development Statistical Bulletin. From China Ministry of Education Ministry of Education website; 2010 [http://www.gov.cn/gzdt/ 2010-08/03/content_1670245.htm], 2011. 
18. XinHua Net: Sexual condition survey of Chongqing college students: ten percent students had homosexual behavior. Chongaing Moring newspaper 2010 [http://news.xinhuanet.com/edu/2003-12/31/content_1255624.htm]

19. Ruan Y, Li D, Li X, Qian H, Shi W, Zhang X, Yang Z, Zhang X, Wang C, Liu Y: Relationship between syphilis and HIV infections among men who have sex with men in Beijing, China. Sex Transm Dis 2007, 34(8):592-597.

20. Fleming DT, Wasserheit JN: From epidemiological synergy to public health policy and practice: the contribution of other sexually transmitted diseases to sexual transmission of HIV infection. Sex Transm Infect 1999, 75:3-17.

21. Wang $S$, Wang $L$, Qi H, Rong X: A Survey for the university students on HIV voluntary test and the awareness status of AIDS knowledge. Chin $J$ Health Educ 2007, 23(6):447-478.

22. Xu J, Zhang H, Zhang Y, Wang J, Zhu Y, Li Z, Hu Z: The prevalence of syphilis and HIV infection among young men who have sex with men in Hefei city. Chin J of Behavioral Med Sci 2007, 16(3):205-207.

23. Xu Z, Ma S, Wang R: One HIV infection case report among MSM student. Chin J Sch Health 2007, 48(4):367-367.

24. Global Network: Zhejiang Province prepares to learn HIV prevalence among college students by physical examination. 2010 [http://china. huanqiu.com/roll/2010-07/919670.html].

25. Zhejiang Online: There is no high risk population but high risk behaviors: Face-to-face between students to AIDS patient. China Daily 2010 [http:// www.chinadaily.com.cn/dfpd/zhejiang/2010-06-22/content_482573.html].

26. Xinhua: Net HIV epidemic is increasing among China aged population and campus students. 2010 [http://www.chain.net.cn/zhxw/xwbd/27868. $\mathrm{htm}$ ].

27. Wong CY, Tang CS: Sexual practices and psychosocial correlates of current condom use among Chinese gay men in Hong Kong. Arch Sex Behav 2004, 33(2):159-167.

28. Boyer CB, Sieverding J, Siller J, Gallaread A, Chang YJ: Youth united through health education: Community-level, peer-led outreach to increase awareness and improve noninvasive sexually transmitted infection screening in urban African American youth. $J$ Adolesc Health 2007, 40(6):499-505.

29. Kelly JA, St Lawrence JS, Diaz YE, Stevenson LY, Hauth AC, Brasfield TL, Kalichman SC, Smith JE, Andrew ME: HIV risk behavior reduction following intervention with key opinion leaders of population: an experimental analysis. Am J Public Health 1991, 81(2):168-171.

30. Kelly JA, St Lawrence JS, Stevenson LY, Hauth AC, Kalichman SC, Diaz YE, Brasfield TL, Koob JJ, Morgan MG: Community AIDS/HIV risk reduction: the effects of endorsements by popular people in three cities. Am J Public Health 1992, 82(11):1483-1489.

31. Kelly JA, Murphy DA, Sikkema KJ, McAuliffe TL, Roffman RA, Solomon LJ, Winett RA, Kalichman SC: Randomised, controlled, community-level HIVprevention intervention for sexual-risk behaviour among homosexual men in US cities. J Lancet 1997, 350(9090):1500-1505.

32. Coplan PM, Gortmaker S, Hemandez-Avila M, Spiegelman D, Uribe-Zuuiga P, Mueller NE: Human immunodeficiency virus infection in Mexico City: rectal bleeding and anal warts as risk factors among men reporting sex with men. Am J Epidemiol 1996, 144(9):817-827.

33. Ma Y, Li Z, Zhang K: HIV was first discovered among injection drug users in China. Chin J Epidemiol 1990, 11:184-185.

34. Carey JW, Mejia R, Bingham T, Ciesielski C, Gelaude D, Herbst JH, Sinunu M, Sey E, Prachand N, Jenkins RA: Drug use, high-risk sex behaviors, and increased risk for recent HIV infection among men who have sex with men in Chicago and Los Angeles. AIDS Behav 2009, 13(6):1084-1096.

35. Ostrow DG, Plankey MW, Cox C, Li X, Shoptaw S, Jacobson LP, Stall RC: Specific sex drug combinations contribute to the majority of recent HIV seroconversions among MSM in the MACS. JAIDS 2009, 51(3):349-355.

\section{Pre-publication history}

The pre-publication history for this paper can be accessed here: http://www.biomedcentral.com/1471-2458/11/287/prepub

\section{doi:10.1186/1471-2458-11-287}

Cite this article as: Xu et al:: A cross-sectional study of HIV and syphilis infections among male students who have sex with men (MSM) in northeast China: implications for implementing HIV screening and intervention programs. BMC Public Health 2011 11:287.

\section{Submit your next manuscript to BioMed Central and take full advantage of:}

- Convenient online submission

- Thorough peer review

- No space constraints or color figure charges

- Immediate publication on acceptance

- Inclusion in PubMed, CAS, Scopus and Google Scholar

- Research which is freely available for redistribution

Submit your manuscript at www.biomedcentral.com/submit
Biomed Central 